\title{
Understanding the direct and indirect costs of patients with
}

\section{schizophrenia [version 1; peer review: 1 approved, 1 approved}

\section{with reservations]}

\author{
Kazuhiro Tajima-Pozo1, María Jesús de Castro Oller ${ }^{1}$, Adrian Lewczuk ${ }^{1,2}$, \\ Francisco Montañes-Rada1 \\ 1Universidad Rey Juan Carlos de Madrid, Madrid, 28933, Spain \\ ${ }^{2}$ Medical University of Warsaw, Warsaw, 61, Poland
}

V1 First published: 06 Jul 2015, 4:182
https://doi.org/10.12688/f1000research.6699.1

Latest published: 06 Aug 2015, 4:182

https://doi.org/10.12688/f1000research.6699.2

\begin{abstract}
Background: Schizophrenia is a disabling mental disorder with high prevalence and that usually requires long-term follow-up and expensive lifelong treatment. The cost of schizophrenia treatment consumes a significant amount of the health services' budget in western countries.

Objective: The aim of the study was to find out about the costs related to schizophrenia across different european countries and compare them.

Results: Schizophrenia treatment costs an estimated 18 billion euros annually worldwide. The direct costs associated with medical help are only part of the total expenditure. The indirect costs are an equally (or even more)important part of the total cost. These expenses are related to the lack of productivity of schizophrenic patients and the cost that relatives have to bear as a result of taking care of their affected relatives.

Conclusions: Although data on the cost of schizophrenia may vary slightly between different european countries, the general conclusion that can be drawn is that schizophrenia is a very costly disorder. Not only because of direct costs related to medical procedures, but also due to the non-medical (indirect) costs. Together this suggests the need to investigate cost-efficient strategies that could provide a better outcome for schizophrenic patients, as well as the people who care for them.
\end{abstract}

\section{Keywords}

Schizophrenia costs, Europe, indirect and direct costs, disability, antipsychotic

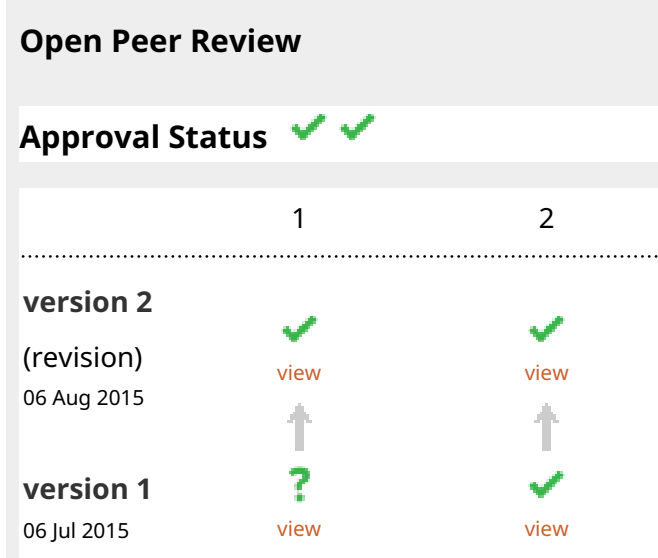

1. Lucas Giner, University of Seville, Seville,

Spain

Diego De La Vega, Complejo Hospitalario

Universitario de Huelva, Huelva, Spain

2. Mayumi Okuda, Columbia University Medical Center, New York, USA

Any reports and responses or comments on the article can be found at the end of the article. 
Corresponding author: Kazuhiro Tajima-Pozo (kazutajima@hotmail.com)

Competing interests: The authors declared no competing interests.

Grant information: The author(s) declared that no grants were involved in supporting this work.

Copyright: ( 2015 Tajima-Pozo K et al. This is an open access article distributed under the terms of the Creative Commons Attribution License, which permits unrestricted use, distribution, and reproduction in any medium, provided the original work is properly cited.

How to cite this article: Tajima-Pozo K, de Castro Oller MJ, Lewczuk A and Montañes-Rada F. Understanding the direct and indirect costs of patients with schizophrenia [version 1; peer review: 1 approved, 1 approved with reservations] F1000Research $2015,4: 182$ https://doi.org/10.12688/f1000research.6699.1

First published: $06 \mathrm{Jul}$ 2015, 4:182 https://doi.org/10.12688/f1000research.6699.1 


\section{Introduction}

Why is schizophrenia such a costly disease?

Schizophrenia is a chronic psychiatric condition that affects around $1 \%$ of the population worldwide ${ }^{1-4}$. It is one of the most stigmatizing diseases of all time ${ }^{3,5}$. Schizophrenic disorders present with a wide range of symptoms, both positive and negative, leading to cognitive, social and functional impairment. Therefore most schizophrenic patients are considered disabled and claim benefits ${ }^{6}$. The debilitating nature of the disorder means that patients receive lifelong treatment, and a large proportion of them need to be admitted to a hospital inpatient unit on multiple occasions throughout their lifetime ${ }^{1-3}$.

All of the above factors lead to the high costs associated not only with the treatment of schizophrenia but also related to social impairment $^{3,7}$. By these we mean the inability to work and also the way that schizophrenia affects the patients' environment. The need to take care of and support schizophrenic relatives is a major reason for members of their families to take sick leave or even sacrifice their own career $^{3,8}$. All of this, plus the high expense associated with the newest antipsychotic drugs, makes the costs of schizophrenia management as high as $3 \%$ of the total healthcare budget of western countries ${ }^{1}$.

The aim of this paper is to give a global view on the problem and to emphasize certain cost-inducing aspects of schizophrenia management by reviewing past research on the costs of schizophrenia management. Only some of the data are comparable, e.g. annual expenses on schizophrenia treatment, expenses per capita on schizophrenia treatment, while we can not compare the other data we found in such a manner. Nevertheless we decided to include them to give the reader a broader view on the matter. As such, taking into account these possible and obvious differences concerning data collecting methods used by the particular researchers, as well as different years in which the researchers conducted their studies, the comparison can only estimate the true cost of schizophrenia treatment.

Understanding the direct and indirect costs of schizophrenia the clue to the problem

Regardless of the authors' origin, they all agree unanimously that the costs associated with the treatment and care of schizophrenic patients can be divided into two important groups: direct and indirect $\operatorname{costs}^{2-4,8,9}$. The direct costs of treating schizophrenia include cost of hospitalization (short- and long-term), outpatient follow-up, residential and day care, pharmaceutical interventions, laboratory testing and social security payments, whereas the indirect costs are mainly related to the loss of productivity ${ }^{1,3,10,11}$. The age of onset of the disorder, usually in the late teens or early 20 s, can preclude patients from even starting to work ${ }^{12}$. Later on, most of the patients receive benefits for incapacity for work due to disability ${ }^{6}$. Nowadays, most schizophrenic patients receive a disability certificate and eventually do not work. Up to $80 \%$ of schizophrenic patients in the UK do not have paid employment ${ }^{3}$. In Italy and Spain, three out of four patients with schizophrenia are excluded from the job market ${ }^{9,13}$. Thus, some authors consider the loss of productivity as accounting for the majority of the indirect costs ${ }^{4}$.

Speaking of indirect costs, it is also important to consider the indirect cost associated with caregivers to schizophrenic patients, who contribute with their time and in-kind services (Table 1). Therein lies the issue. The real number of people affected by schizophrenia is much bigger than just the number of the patients. According to some authors, direct and indirect costs are approximately equal ${ }^{14}$, whereas others suggest that indirect costs can outnumber the direct ones up to three or four times ${ }^{11,15}$.

Some authors also distinguish a third group of costs, called "intangible costs" 3 . These are expenses of a non-financial nature. They try to accomplish the hard task of reflecting the patients' quality of life, including side-effects of pharmaceutical interventions and stress and anxiety, both caused by the disease itself and also the treatment process. Although this group might have no direct financial impact, it is worth considering these factors as they probably affect the cooperation between patient and health providers ${ }^{16,17}$. Furthermore, we can also take into account the intangible costs of the caregivers of schizophrenic patients ${ }^{3}$. Daily care of a schizophrenic relative can be a very challenging and exhausting experience ${ }^{3,18}$. Social stigma and the lack of sympathy and understanding may lead to anxiety and depression in caregivers as well as sufferers ${ }^{5}$. This could damage the relationship between the caregiver and the caretaker, which may lead to an increased rate of patient deterioration and worse prognosis in the long-term ${ }^{18}$.

\section{Data collection in relation to the aims of this article}

The main part of data used in this article come from psychiatric wards in Spain, France, Sweden, Poland, United Kingdom and Ukraine (Table 2, Table 3 and Table 4). Data from recent USA research have also been included for comparison purposes. Although some of the methods used for data collection vary, depending on the country and researchers, the general idea of this article is to get a global view on the subject. Thus, some estimations can be made and their legitimacy is consistent as shown by the similarities between the results.

Table 1. Types of schizophrenia-related costs.

\begin{tabular}{|l|l|l|l|}
\hline $\begin{array}{l}\text { Type of } \\
\text { costs }\end{array}$ & Direct & Indirect & Intangible \\
\hline Examples & $\begin{array}{l}\text { - hospitalisation (short- and } \\
\text { long-term) } \\
\text { - outpatient follow-up } \\
\text { - residential and day care } \\
\text { - drugs } \\
\text { - laboratory testing }\end{array}$ & $\begin{array}{l}\text { - loss of productivity } \\
\text { - the cost that the care-givers bear by } \\
\text { contributing their time and in-kind services }\end{array}$ & $\begin{array}{l}\text { - side-effects of the drugs } \\
\text { - social security payments and anxiety caused by the } \\
\text { - disorder itself and the treatment process }\end{array}$ \\
\hline
\end{tabular}


Table 2. Cost of schizophrenia in France, Spain, United Kingdom and USA are shown in table 2. Direct, indirect and total cost are defined by authors across different articles with similar criteria which have been discussed in the Introduction section. Total cost is defined as a sum of the direct and indirect cost. The table also contains the proportion of the cost of pharmaceutical treatment (Drug cost) in relation to the total cost.

\begin{tabular}{|c|c|c|c|c|c|}
\hline Country & Direct costs & Indirect costs & Total cost & $\begin{array}{c}\text { Drug cost in } \\
\text { relation to } \\
\text { the total cost }\end{array}$ & Authors and year \\
\hline France & $\begin{array}{c}1581 \\
\text { milion } €\end{array}$ & $\begin{array}{c}2214 \\
\text { milion } €\end{array}$ & $\begin{array}{c}3534 \\
\text { milion } €\end{array}$ & $16,1 \%$ & $\begin{array}{c}\text { Emmanuelle Sarlon et al. 2012 } \\
\text { (data comes from 1998-2002) }\end{array}$ \\
\hline Spain & $\begin{array}{c}1044 \\
\text { milion } €\end{array}$ & $\begin{array}{c}926 \\
\text { milion } €\end{array}$ & $\begin{array}{c}1970 \\
\text { milion } €\end{array}$ & $12,8 \%$ & $\begin{array}{c}\text { Juan Oliva-Moreno et al. 2006 (data } \\
\text { comes from 2002) }\end{array}$ \\
\hline UK & $\begin{array}{c}714 \\
\text { milion } £\end{array}$ & $\begin{array}{c}1886 \\
\text { milion } £\end{array}$ & $\begin{array}{c}2600 \\
\text { milion } £\end{array}$ & $4 \%$ & Martin Knapp, 1997 (data comes \\
\hline USA & $\begin{array}{c}32051 \\
\text { milion } \$\end{array}$ & $\begin{array}{c}32378 \\
\text { milion } \$\end{array}$ & $\begin{array}{c}64429 \\
\text { milion } \$\end{array}$ & $8 \%$ & Joseph P. McEvoy 2007 (data by \\
\hline
\end{tabular}

Table 3. Examples of schizophrenia costs in Poland (in the city of Poznan) and Ukraine (in the city of Lviv) - comparison. The data coming from these two eastern European countries only includes direct costs (total cost=total direct cost) 50 patients were included in the search in Poland and 58 patients in Ukraine. (Tomasz Zaprutko et al., 2014; data comes from years 2010-2011)4.

\begin{tabular}{|c|c|c|c|}
\hline City & $\begin{array}{c}\text { Number of } \\
\text { patients }\end{array}$ & Total direct cost & $\begin{array}{c}\text { Pharmacotherapy } \\
\text { cost in relation to } \\
\text { the total cost }\end{array}$ \\
\hline Poznan (Poland) & 50 & $160,572.08 €$ & $6,60 \%$ \\
\hline Lviv (Ukraine) & 58 & $30,943.37 €$ & $6,43 \%$ \\
\hline
\end{tabular}

Table 4. Schizophrenia costs in Sweden are presented in table 4. Data from a study that lasted 5 years ${ }^{4}$. Mean values of indirect, direct and total costs per patient. Percentage of drugs participation in the total cost is included.

\begin{tabular}{|c|c|c|c|c|}
\hline Sweden & Direct cost & Indirect cost & Total cost & $\begin{array}{c}\text { Drugs cost in relation } \\
\text { to the total cost }\end{array}$ \\
\hline Mean values & $33,892.5 €$ & $25,652.5 €$ & $59,545.0 €$ & $3,8 \%$ \\
\hline
\end{tabular}

\section{Methods}

The research data for this article was collected by the use of the PubMed database in April 2015, having used key words: "schizophrenia costs in Europe", "(indirect and direct costs) schizophrenia", "schizophrenia costs worldwide”, "schizophrenia costs United States”, "schizophrenia and disability", "antipsychotic treatment in Europe" as a part of the abstract, title or included anywhere in the whole paper. We analysed 41 articles that we managed to find according to the criteria we adopted.

We wanted to include only the latest data coming from research conducted after year 2000. Due to the fact that there has been very little research done in this field in general we decided to analyse papers from the whole PubMed dataset. We did however exclude the earliest data (Australia 1976; USA 1975, 1985; Netherlands 1989) since we found them irrelevant (for example, at that time second-generation antipsychotic drugs were not used and they account for a significant part of medication costs).

The nature of data varies between different authors. Some articles give total amounts of money in relation to the direct and indirect schizophrenia treatment costs in a particular country. The others give numbers per patient. The percentage approximations of pharmacological costs are also present, directly obtained from papers.

We included only those articles showing general information about costs of schizophrenia across different countries, and excluded those ones related only to specific services, like acute inpatient 
units, where stated costs did not include rehabilitation expenses or full treatment options, what could lead to important bias when comparing pharmacological expenses or indirect costs.

\section{Results and discussion}

This paper points at the magnitude of the problem of schizophrenia treatment costs and estimates the huge impact that this mental disorder has on patients' environment and society at a financial level across several different countries ${ }^{3,7,16}$.

What definitely strikes attention when it comes to available data is that the estimated indirect cost represents a significant part of the total cost of schizophrenia. It is particularly important to bear that in mind in order to manage schizophrenia efficiently.

The other conclusion that can be drawn from our research is that the cost of pharmaceutical treatment doesn't contribute significantly to the total cost of treatment ${ }^{7,16}$. This statement is equally consistent for both Western (Table 2 shows percentages which range from $4 \%$ in UK to $16,1 \%$ in France; Table 4 shows the percentage in Sweden $-3,8 \%$ ) and Eastern European countries such as Poland and Ukraine (Table 3). These results may suggest important differences on the cost of non-pharmaceutical care provided across countries ${ }^{1}$, which need further investigation.

\section{Limitations of study and recommendations for future research}

Collected data across different studies vary in terms of the number of patients included or hospitals involved across different investigations. An exact comparison between all papers is obviously not possible, but certain estimations can be made.

In some countries, like France and UK, the indirect costs outnum-

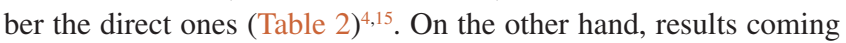
from Spain and USA suggest that both types of cost are equally important in total ${ }^{12,14}$. To better understand this result we need to consider the differences across particular studies regarding design and methods used. For instance, the approach to calculate the cost of lost workforce varies between the countries, which could lead to some of the differences observed. In Spain, the official registries do not reflect the work force lost by people who have never even started a job - and this group of people accounts for a large proportion of schizophrenic patients since the onset of the disorder (and so the problems with getting or maintaining employment) may occur early in life, before young people begin their career ${ }^{14}$.
Therefore, it could be possible that the indirect costs are even higher in the countries who register its workforce in this way.

How to improve the situation?

Many authors raise the issue of patients' adherence to prescribed therapy. An optimal control of schizophrenic symptoms is proven to lead to fewer number of hospitalizations and less need to use other approaches of formally organized patient care ${ }^{19}$. Although good adherence to treatment means no reduction in the budget for pharmaceutical interventions, this cost does not seem to represent a significant percentage when compared to total cost of the illness (drugs costs vs. total costs - see Table 2, Table 3 and Table 4). Good psychoeducational programs and building insight about the disease and its management makes patients feel more secure and thus more cooperative $^{1,3}$.

When the symptoms of schizophrenia remain under control, patients experience a smaller risk of mental impairment and social exclusion which extends to participation in work opportunities ${ }^{20}$. So it is of crucial importance to a investigate whether better control of symptoms could allow patients to get a chance to attain and keep a job, and how this fact could affect their quality of life. Moreover, we should consider how this could be used to lighten the burden of care that relatives and caregivers experience and thus reduce the indirect costs which make up a significant part of the costs of this illness.

Therefore, it is our suggestion that the future of schizophrenia treatment should address more carefully important elements of the financial aspects of the disease, such as cost-efficacy of treatment, including psychological therapies and psychoeducational approaches for both patients and their families. A wider view on the matter is needed.

\section{Author contributions}

The manuscript was written by Adrian Lewczuk and Dr. TajimaPozo. Dr. Castro and Dr. Montañes-Rada contributed to analysis of the data and identification of suitable references. All authors have seen and agreed to the final content of the manuscript.

\section{Competing interests}

The authors declared no competing interests.

Grant information

No funding was involved in supporting this research.
1. Knapp M: Schizophrenia costs and treatment cost-effectiveness. Acta Psychiatr Scand Suppl. 2000; 407: 15-8. PubMed Abstract | Publisher Full Text

2. Sarlon E, Heider D, Millier A, et al: A prospective study of health care resource utilisation and selected costs of schizophrenia in France. BMC Health Serv Res. 2012; 12: 269-76.

PubMed Abstract | Publisher Full Text | Free Full Text

3. Knapp M: Costs of schizophrenia. Br J Psychiatry. 1997; 171(6): 509-18. PubMed Abstract | Publisher Full Text

4. Lindström E, Eberhard J, Neovius M, et al:: Costs of schizophrenia during 5 years. Acta Psychiatr Scand Suppl. 2007: 116(435): 33-40. PubMed Abstract | Publisher Full Text

5. Phelan JC, Bromet EJ, Link BG: Psychiatric illness and family stigma. Schizophr Bull. 1998; 24(1): 115-26. PubMed Abstract | Publisher Full Text

6. Jonsson $\mathrm{U}$, Alexanderson $\mathrm{K}, \mathrm{Kjeldgård} \mathrm{L,} \mathrm{et} \mathrm{al.:} \mathrm{Psychiatric} \mathrm{diagnoses} \mathrm{and} \mathrm{risk} \mathrm{of}$ suicidal behaviour in young disability pensioners: prospective cohort studies of all 19-23 year olds in Sweden in 1995, 2000, and 2005, respectively. PLOS One. 2014; 9(11): e111618. PubMed Abstract | Publisher Full Text | Free Full Text 
7. Salize HJ, McCabe R, Bullenkamp J, et al.: Cost of treatment of schizophrenia in six European countries. Schizophr Res. 2009; 111(1-3): 70-7. PubMed Abstract | Publisher Full Text

8. Becker T, Knapp M, Knudsen HC, et al:: The EPSILON study of schizophrenia in five European countries. Design and methodology for standardising outcome measures and comparing patterns of care and service costs. Br J Psychiatry. 1999; 175: 514-21.

PubMed Abstract | Publisher Full Text

9. Oliva-Moreno J, López-Bastida J, Osuna-Guerrero R, et al:: The costs of schizophrenia in Spain. Eur J Health Econ. 2006; 7(3): 182-88. PubMed Abstract | Publisher Full Text

10. Vázquez-Polo FJ, Negrín M, Cabasés JM, et al.: An analysis of the costs of treating schizophrenia in Spain: a hierarchical Bayesian approach. $J$ Ment Health Policy Econ. 2005; 8(3): 153-65. PubMed Abstract

11. Davies LM, Drummond MF: Economics and schizophrenia: the real cost. Br J Psychiatry Suppl. 1994; 25: 18-21. PubMed Abstract

12. McEvoy JP: The costs of schizophrenia. J Clin Psychiatry. 2007; 68(Suppl 14): $4-7$.

PubMed Abstract

13. Garattini L, Barbui C, Clemente R, et al.: Direct costs of schizophrenia and related disorders in Italian community mental health services: a multicenter, prospective 1-year followup study. Schizophr Bull. 2004; 30(2): 295-302. PubMed Abstract

14. Rupp A, Keith SJ: The costs of schizophrenia. Assessing the burden. Psychiatr Clin North Am. 1993; 16(2): 413-23.

PubMed Abstract

15. Andrews G, Sanderson K, Corry J, et al.: Cost-effectiveness of current and optimal treatment for schizophrenia. Br J Psychiatry. 2003; 183: 427-35; discussion 436.

PubMed Abstract | Publisher Full Text

16. Knapp M, Mangalore R, Simon J: The global costs of schizophrenia. Schizophr Bull. 2004; 30(2): 279-93.

PubMed Abstract | Publisher Full Text

17. Balak N, Elmaci I: Costs of disorders of the brain in Europe. Eur J Neurol. 2007; 14(2): e9.

PubMed Abstract | Publisher Full Text

18. Mari JJ, Streiner D: The effects of family intervention on those with schizophrenia. Schizophrenia module, Cochrane Database of Systematic Reviews. 1996.

19. Lindström E, Bingefors K: Patient compliance with drug therapy in schizophrenia. Economic and clinical issues. Pharmacoeconomics. 2000; 18(2): 106-24. PubMed Abstract | Publisher Full Text

20. Zaprutko T, Kus K, Bilobryvka R, et al:: Schizophrenia and Employment: Evaluation From Professionals Point of View. Psychiatr Q. 2015. PubMed Abstract | Publisher Full Text 


\section{Open Peer Review}

\section{Current Peer Review Status:}

\section{Version 1}

Reviewer Report 03 August 2015

https://doi.org/10.5256/f1000research.7196.r9352

(C) 2015 Okuda M. This is an open access peer review report distributed under the terms of the Creative Commons Attribution License, which permits unrestricted use, distribution, and reproduction in any medium, provided the original work is properly cited.

\section{Mayumi Okuda}

Department of Psychiatry, New York State Psychiatric Institute, The College of Physicians and Surgeons, Columbia University Medical Center, New York, NY, USA

The article offers a concise, brief summary of an important topic. The following are minor revisions that will improve the manuscript

1. Changing the terminology "schizophrenic patients" to "patients with schizophrenia" or "individuals with schizophrenia".

2. In the abstract the objective states the aim is to report on the costs of schizophrenia across different European countries, yet the results states "18 billion euros worldwide." Given that the manuscript reviews economic studies in Europe, it should be modified to focus on European findings.

3. The last few sentences in paragraph 3 of the introduction describe limitations of this review; these sentences should be described in the methods section. It is not completely clear to me what the authors are referring to when they mention "other data" that could not be compared.

4. A paragraph following the introduction or within the introduction detailing the types of costs that are typically measured in these type of studies could replace table 1.

5. Detailing the types of costs that were measured in the different studies would be a valuable contribution to Table 2.

Competing Interests: No competing interests were disclosed.

I confirm that I have read this submission and believe that I have an appropriate level of expertise to confirm that it is of an acceptable scientific standard. 
Author Response 03 Aug 2015

Kazuhiro Tajima-Pozo, Universidad Rey Juan Carlos de Madrid, Madrid, Spain

Thanks for your review, we have made the following changes in our latest version

1. Change the terminology "schizophrenic patients" to "patients with schizophrenia" or "individuals with schizophrenia".

2. The last few sentences in paragraph 3 have been moved to the methods section.

3. A brief paragraph following the introduction of table 1 have been included.

4. A brief paragraph following the introduction of table 2 have been included.

Best regards and thanks for your quick and good review of our paper

Competing Interests: No competing interests were disclosed.

Reviewer Report 16 July 2015

https://doi.org/10.5256/f1000research.7196.r9406

(c) 2015 Giner L et al. This is an open access peer review report distributed under the terms of the Creative Commons Attribution License, which permits unrestricted use, distribution, and reproduction in any medium, provided the original work is properly cited.

\section{Lucas Giner}

Department of Psychiatry, Faculty of Medicine, University of Seville, Seville, Spain

Diego De La Vega

Unidad de Salud Mental Comunitaria de Huelva, Complejo Hospitalario Universitario de Huelva, Huelva, Spain

Brief and nice review of an important topic related to economic cost of schizophrenia. Results are presented clear. However, I think that tables with examples are not necessary and should be considered to be deleted. The text does not need any change in my consideration.

Competing Interests: No competing interests were disclosed.

We confirm that we have read this submission and believe that we have an appropriate level of expertise to confirm that it is of an acceptable scientific standard, however we have significant reservations, as outlined above.

Author Response 16 Jul 2015

Kazuhiro Tajima-Pozo, Universidad Rey Juan Carlos de Madrid, Madrid, Spain 
Thanks for your quick review and your comments.

Competing Interests: No competing interests were disclosed.

\section{Author Response 20 Jul 2015}

Kazuhiro Tajima-Pozo, Universidad Rey Juan Carlos de Madrid, Madrid, Spain

According to the reviewer comments, we have deleted table 4, and we have maintained table 1, 2 and 3. I hope that this changes could contribute to the final acceptance of the paper.

Competing Interests: No competing interests were disclosed.

The benefits of publishing with F1000Research:

- Your article is published within days, with no editorial bias

- You can publish traditional articles, null/negative results, case reports, data notes and more

- The peer review process is transparent and collaborative

- Your article is indexed in PubMed after passing peer review

- Dedicated customer support at every stage

For pre-submission enquiries, contact research@f1000.com 